\title{
PLANNING STRATEGY OF CONTAINER LAYOUT FOR AN OPTIMAL ENERGY IMPACT
}

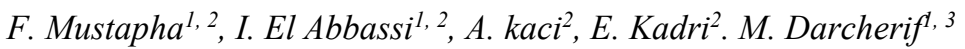 \\ ${ }^{1}$ Laboratory of Research on Industrial Eco-innovation and Energy, ECAM-EPMI, Cergy-Pontoise \\ ${ }^{2}$ Laboratory of Mechanic Materials of Civil Engineering, University of Cergy-Pontoise. \\ ${ }^{3}$ Laboratoire QUARTZ, (EA 7393), University Paris-Seine.
}

\begin{abstract}
Today, the building sector represents $44 \%$ of the energy consumed in France, far ahead of transportation, which makes it one of the key areas in the fight against global warming and invite the community to the energy transition. The shape, now is just a factor that is considered only aesthetically and not for its energy impact. The objective consumption of the various surfaces of the living space plays a crucial role in encouraging the energy transition in the building and civil engineering sector. In addition, the shape of the building as a whole, as well as the interior design, and the distribution of spaces have a significant influence on energy efficiency [1]. Our contribution in this paper is to make a numerical analysis of the impact of a building conception on its energy bill, more precisely, the influence of the geometry resulting from the assembly of these containers as well as their layout, and their orientations. The container represents a unit that is part of a complex and multiple systems, which offers a new opportunity for architects to rethink their designs both in terms of aesthetics and impact on the skyline as well as in the use of innovative, environmentally friendly and sustainable materials. In this paper we will focus on a purely formal analysis first with TRNSYS, and then we will start with an elementary modelling meeting the criteria of sustainability (eco-container), in those to lead to a design that is economical and energy efficient.
\end{abstract}

\section{Introduction}

Currently, housing faces many limitations, these constraints are reflected in the fact that they satisfy criteria common not only to users but also to the environment with which it interacts both directly and indirectly, these criteria are economic, energetic and aesthetic, rethinking the design method is not limited to the bioclimatic design approach, today the integration of these principles is no longer sufficient, the imperatives of the energy transition have become the priority, the role of the architect is to reduce the energy bill without encroaching on the comfort of the occupant.

The field of building and construction is an energyconsumer sector; the concept of bioclimatic architecture is one of the answers to the issues raised. Energyefficient architecture includes several criteria's to be taken into consideration, such as the orientation, the integration of the building into the territory and the nature of the materials used [2].

Among all these parameters that are mentioned, the objective is to optimize the overall consumption of the project, the envelope is very important, it is impacting the gains and loses heat and therefore energy, making changes on it is to influence positively the energy balance of the construction. These changes can be at the level of materials, their thicknesses, or shape, compactness, window wall ratio (WWR), which plays a major role in the amount of gained energy or lost [3]. This passive strategies on the geometry of all types of buildings including dwellings represent also an aesthetic factor, this intervention is crucial, indeed it must be demonstrated that it does not only impact the visual aspect but reflects its role in energy performance [1] [4]. The architects must take these gain and the aesthetic aspects into account from the design phase [5]. In addition, work has already been done on this subject, which shows that the compactness of the building and the type of glazing used also have a significant impact, with an optimization of exposure in order to maximize free energy inputs [6].

In this paper we will focus on the impact of the shape on energy efficiency of a container type building, the metallic box is standardised [7] by the International Organization for Standardization. Our objective here is to compare the performance of these to transform them into sustainable housing. For this study, we will choose the standard container: ISO 20 feet with the following dimensions L: $6058 \mathrm{~mm}$; H: $2591 \mathrm{~mm}$; I: $2438 \mathrm{~mm}$. In order to create a bioclimatic container, it is necessary to create one or more examples of containers, analyse their thermal behaviour and finally determine their energy performance. The simulation being done on TRNSYSa by applying the bioclimatic design requirements.

a TRNSYS is a flexible graphically based software environment used to simulate the behavior of transient systems

\footnotetext{
* Corresponding author: f.mustapha@ecam-epmi.com
} 


\section{Methodology:}

\subsection{Model definition:}

We choose to use four containers in order to precede our numerical simulations. All these units have the same wall composition, the same WWR, and the same volume $33.2 \mathrm{~m}^{3}$ for each one.

The wall composition is as described in Erreur ! Source du renvoi introuvable. from inside to outside.

\subsection{Simulation process:}

We decided to start by simulating a first model that will be our reference, this one is composed of four containers, (see figure 1), for the others we carried with the same number of containers in order to keep a volume and a livable surface equal to the reference model, which is $13.86 \mathrm{~m}^{2} \mathrm{x} 4$, same for the wall types and their thermal characteristics.

The simulation models are represented on the figure, the latter are chosen in such a way as to gain in aesthetics with a play of volume that impacts the visual aspect and therefore and a more dynamic architectural reading.

To start the simulation via TRNSYS, we have set inputs, which are as follows:

Meteorological data: the weather of Trappes Paris France.

Atmospheric pressure: $101325 \mathrm{~Pa}$.

Heat of vaporization of water: $2454 \mathrm{~kJ} / \mathrm{kg}$.

Stefan Boltzmann Constant: 2,041e-007 kJ/hm²K.

Approximation of average surface temperature: $293.15^{\circ} \mathrm{K}$

Table 1. wall type of the container used as a defined model

\begin{tabular}{|c|c|c|c|}
\hline Wall type & Materials & $\begin{array}{l}\text { Thickness } \\
\text { (cm) }\end{array}$ & $\begin{array}{l}\text { U-Value } \\
\left(\mathrm{W} / \mathrm{m}^{2} \mathrm{~K}\right)\end{array}$ \\
\hline \multirow{4}{*}{ Out wall } & Wall board & 1.3 & \multirow{4}{*}{0.093} \\
\hline & $\begin{array}{c}\text { Wood } \\
\text { Structure } \\
\text { and Air gap }\end{array}$ & 05 & \\
\hline & Hamp wool & 12 & \\
\hline & $\begin{array}{c}\text { Corten steel } \\
\text { structure }\end{array}$ & 05 & \\
\hline \multirow{2}{*}{ Windows } & Glass & 0.4 & \multirow{2}{*}{1.4} \\
\hline & Air gap & 0.16 & \\
\hline
\end{tabular}

\begin{tabular}{|c|c|c|c|}
\hline \multirow{7}{*}{ Roof } & Glass & 04 & \multirow{2}{*}{} \\
\hline & Wall board & 1.3 & \multirow{2}{*}{0.470} \\
\cline { 2 - 3 } & $\begin{array}{c}\text { Wtructure } \\
\text { and Air gap }\end{array}$ & 05 & \multirow{2}{*}{} \\
\cline { 2 - 3 } & Hamp wool & 12 & \multirow{2}{*}{0.852} \\
\cline { 2 - 3 } & $\begin{array}{c}\text { Corten steel } \\
\text { structure }\end{array}$ & 0.5 & \\
\hline Ground & $\begin{array}{c}\text { Keruing } \\
\text { wood }\end{array}$ & 15 & \\
\hline
\end{tabular}

Ours models present the same solar exposition, in fact all the doors are oriented south, and all the windows are oriented west.

When the simulation is launched, results representing an hour-by-hour assessment of the studied area for the whole year, this numerical calculation is based on the following equation:

$$
\begin{gathered}
\frac{\text { DQair }}{d t}=\dot{Q}_{\text {heat }}-\dot{Q}_{\text {cool }}+\dot{Q}_{\text {vent }}+\dot{Q}_{\text {inf }}+\dot{Q}_{\text {trans }} \\
+\dot{Q}_{\text {gainint }}+\dot{Q}_{\text {sol }}[\mathrm{kJ} / \mathrm{h}]
\end{gathered}
$$

Where:

WWR: window-to-wall ratio.

BAL_ENERG: Sum of all the terms of the energy balance, it must be close to 0 .

QHEAT: Indicates the heating requirements required by the system to reach the set temperature.

QSOLGAIN: Indicates internal gains related to solar gains (short waves).

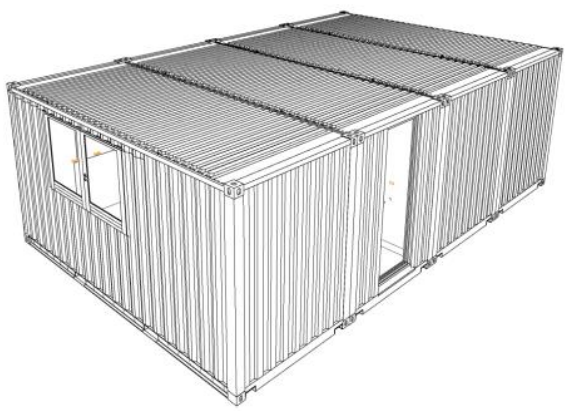

Fig 1. Reference model. 


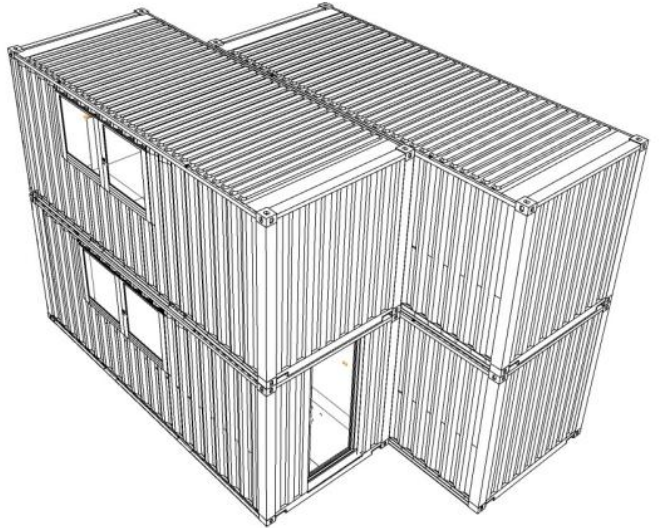

Fig 2. model 1

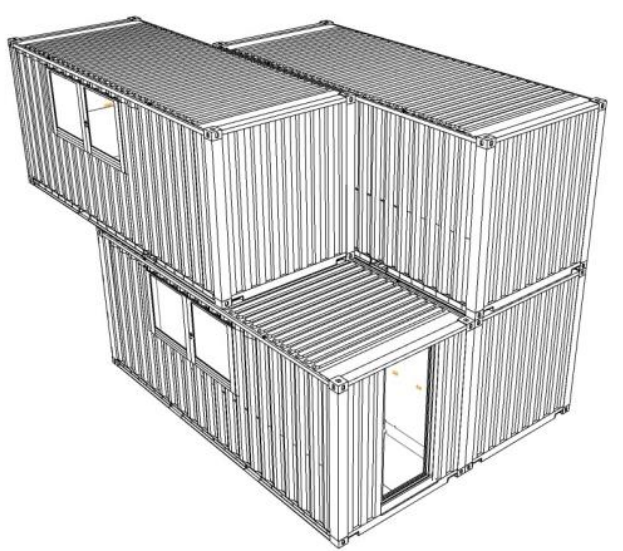

Fig 3. model 2

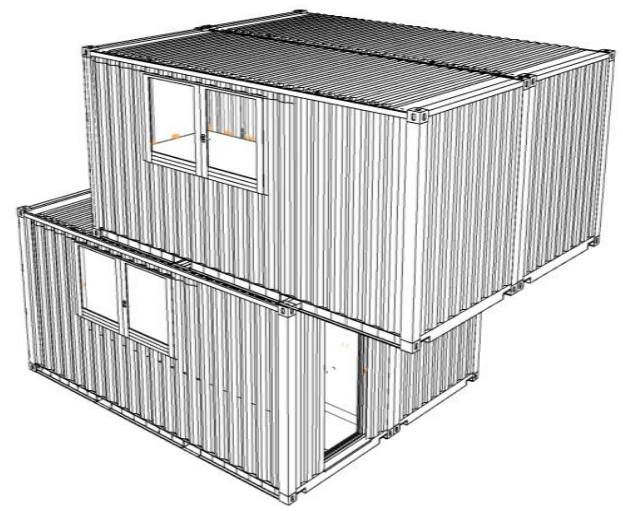

Fig 4. model 3

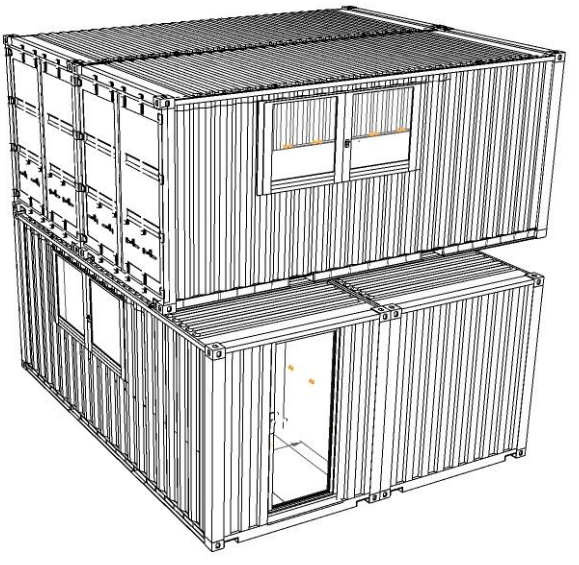

Fig 5. model 4

\section{Results and discussion}

The results show a real energy saving, particularly on heating demand, which has been reduced by an average of $30 \%$ in all the cases studied and is overlapping; however, a particular model (model3) is the one with the best result in terms of energy saving.

Indeed, all simulated models have a larger exposure area (see Table 2).

Increasing exposure helps to exploit more free energy and therefore reduce your heating demand. But the model in question can be uncomfortable in summer. As our model is a container with a metallic outer shell, this highly conductive material makes it possible to benefit from natural heat.

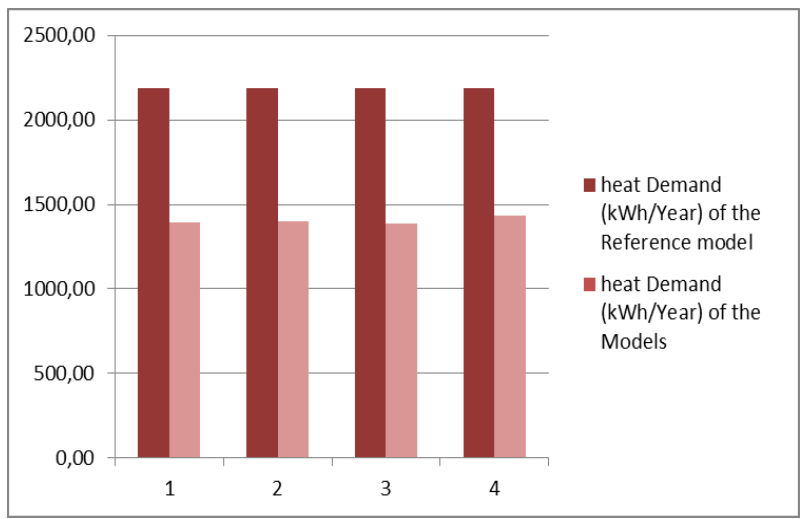

Fig 6; comparison of heat demand during one year between reference model and the others models

The models $1 \& 2$ show a similarity both in terms of surface area and heating demand, but at the formal level the two designs are indeed different, model 1 has two 
additional lateral surfaces while model 2 the additional developed surfaces are horizontal (see figure 6-7).

All these developed models allow not only an energy saving, but also provide a shade that is specific to the shape of the building (see figures 1-5), so this passive design strategy permits an economic saving on the overall cost of the eco-container building.

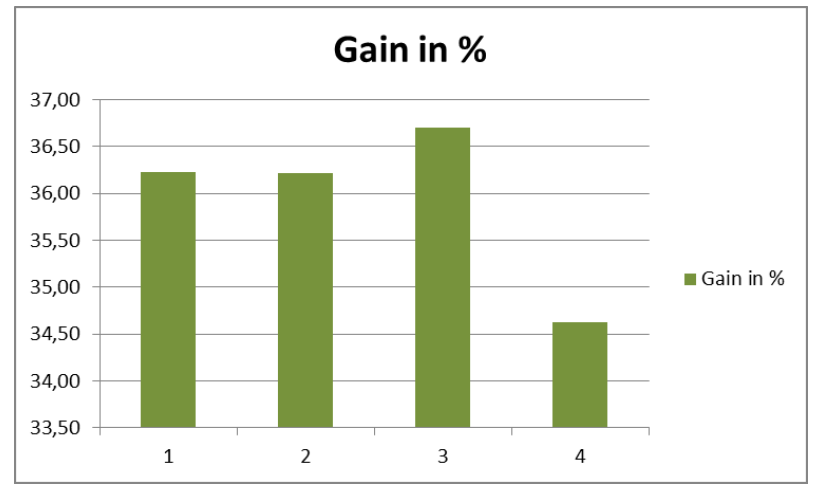

Fig 7. gain in $\%$ on heating demand by models

Model 3 does not have the largest external area (see Table $2 \&$ figure 4). but if you look at model 3 (see figure 4 and figure 7 ), about $36.70 \%$ gain was achieved due not only to the increase in exposure compared to the reference model but also to the reduction in the number of thermal bridges, as well as the optimization of the building's shape, taking into account the overall compactness of the geometry.

Table 2. heat demand during a year and exposed surfaces by model's type

\begin{tabular}{|l|l|l|l|l|l|}
\hline $\begin{array}{l}\text { Model } \\
\text { type }\end{array}$ & $\begin{array}{l}\text { Refere } \\
\text { nce } \\
\text { model }\end{array}$ & $\begin{array}{l}\text { Model } \\
\mathbf{1}\end{array}$ & $\begin{array}{l}\text { Model } \\
\mathbf{2}\end{array}$ & $\begin{array}{l}\text { Model } \\
\mathbf{3}\end{array}$ & $\begin{array}{l}\text { Model } \\
\mathbf{4}\end{array}$ \\
\hline $\begin{array}{l}\text { Surface } \\
\text { expose } \\
\text { d }\end{array}$ & $\begin{array}{l}128.58 \\
\mathrm{~m}^{2}\end{array}$ & $\begin{array}{l}157.77 \\
\mathrm{~m}^{2}\end{array}$ & $\begin{array}{l}151.55 \\
\mathrm{~m}^{2}\end{array}$ & $\begin{array}{l}148.05 \\
\mathrm{~m}^{2}\end{array}$ & $\begin{array}{l}140.37 \\
\mathrm{~m}^{2}\end{array}$ \\
\hline $\begin{array}{l}\text { Heat } \\
\text { deman } \\
\text { d per } \\
\text { year } \\
\text { (kWh/ } \\
\text { Year) }\end{array}$ & 2189.7 & 1396.7 & 1396.4 & 1386.1 & 1431.4 \\
\hline
\end{tabular}

\section{Conclusion}

Bioclimatic design is based on several parameters such as materials, orientation, wall composition, but also the climatic factor. The simulations carried out made it possible to evaluate the annual energy consumption of an eco-container used as elementary cells in our study. With the passive strategy applied to our eco-containers.
With the resulting shape of the containers, the result is interesting not only from an architectural point of view but also in terms of energy. The dynamics of the stacked configurations has allowed the creation of new spaces that can take on another function, such as a terrace or even a garden, from a structural point of view the containers are designed to be stacked and can support a load of 15 containers.

Given the results obtained, we will work on more complex forms and thus enlarge the scale, move on to collective housing and the eco-neighbourhood, with taking into consideration the comfort of the user and compliance with the thermal regulations in force on the site concerned.

\section{References}

1. C.Hachem-Vermette, Sol Ene, pp. 710-721, (2018).

2. G. O. J. a. N. T. Roshan, Ene Pol, 49, pp. 731739, (2012).

3. R. O. J. a. M. G. Pacheco, Ren and Sus Ene Rev, pp. 3559-3573, (2012).

4. M. Medio.S, "Aesthetic vision and sustainability in The New York Times Building ceramic rod facade," (2008).

5. D. M. A. AlAnzi, Ene Con and Man ,50, pp. 822-828, (2009).

6. H. Sozer, Bui Env, 45, pp. 2581-2593, (2010).

7. "International Organization for Standardization," ISO, [Online]. Available: https://www.iso.org/fr/search.html?q=conteneur $\& \mathrm{hPP}=10 \& \mathrm{idx}=$ all_fr $\& \mathrm{p}=1 \& \mathrm{hFR} \% 5$ Bcategory $\% 5 \mathrm{D} \% 5 \mathrm{~B} 0 \% 5 \mathrm{D}=$ standard. 